\title{
A Three-dimensional Finite Element Analysis of Stress Distribution in the Cortical Bone in Single Tooth Implant and Post Core-treated Tooth subjected to variable Loads
}

\author{
${ }^{1}$ Suneetha Rao, ${ }^{2}$ Honey Arora, ${ }^{3}$ Shahul Hameed
}

\begin{abstract}
Purpose: In spite of many advances in the field of prosthetic dentistry, the choice of whether to treat and retain a grossly compromised tooth or to extract and replace with an implant is debatable. Alveolar bone preservation is one of the main criteria to select the treatment option. This is directly affected by the stress generated in the cortical bone under variable loads and is therefore, relevant.
\end{abstract}

Materials and methods: Two three-dimensional finite element models were generated in relation to maxillary second premolar using ANSYS software. Model-I was parallel-tapered titanium implant with screw-retained titanium abutment and porcelain fused to metal (PFM) crown. Model-P was fiber post and composite resin core with PFM crown. Luting cement was resin cement. Both the models were surrounded by homogeneous and isotropic cortical and cancellous bone, and were subjected to variable loads of 300,400 , and $500 \mathrm{~N}$ in axial $\left(0^{\circ}\right)$ and nonaxial $\left(15^{\circ}, 45^{\circ}\right)$ directions.

Results: Stress in the cortical bone in megapascal (MPa) in Model-I/Model-P when subjected to variable loads in newtons $(\mathrm{N})$ in axial direction was $300 \mathrm{~N}-37.6 \mathrm{MPa} / 47.3 \mathrm{MPa} ; 400 \mathrm{~N}-$ $50.2 \mathrm{MPa} / 63.0 \mathrm{MPa} ; 500 \mathrm{~N}-62.7 \mathrm{MPa} / 63.0 \mathrm{MPa} .15^{\circ}-300$ $\mathrm{N}$ - 68.5 MPa/65.9 MPa; $400 \mathrm{~N}$ - 91.3 MPa/87.9 MPa; 500 $\mathrm{N}$ - 114.2 MPa/87.9 MPa. $45^{\circ}-300 \mathrm{~N}-136.3 \mathrm{MPa} / 88.9 \mathrm{MPa}$; $400 \mathrm{~N}-181.8 \mathrm{MPa} / 118.5 \mathrm{MPa} ; 500 \mathrm{~N}-227.2 \mathrm{MPa} / 118.5 \mathrm{MPa}$.

Conclusion: Within the limitation of this study, it was concluded that on axial loading, both the treatment modalities showed no significant difference, but on nonaxial loading, the cortical bone in the implant model showed to have considerably higher stress than post core-treated tooth model. Hence, given a choice, this study favors retaining and restoring a compromised tooth with post core and crown rather than extracting and replacing with an implant.

Keywords: Axial load, Cortical bone, Implant, Nonaxial load, Post core, Prosthodontics.

How to cite this article: Rao S, Arora H, Hameed S. A Threedimensional Finite Element Analysis of Stress Distribution in the Cortical Bone in Single Tooth Implant and Post Core-treated Tooth subjected to variable Loads. Int J Prosthodont Restor Dent 2017;7(1):8-16.

${ }^{1}$ Professor and Head, ${ }^{2}$ Ex-Postgraduate Student, ${ }^{3}$ Senior Lecturer

${ }^{1-3}$ Department of Prosthodontics, Vydehi Institute of Dental Sciences and Research Centre, Bengaluru, Karnataka, India

Corresponding Author: Suneetha Rao, Professor and Head Department of Prosthodontics, Vydehi Institute of Dental Sciences and Research Centre, Bengaluru, Karnataka, India Phone: +919845982879, e-mail: neetha7879@gmail.com
Source of support: Nil

Conflict of interest: None

\section{INTRODUCTION}

Severely compromised but salvageable teeth are a common clinical presentation and need to be treated after thorough assessment of various factors affecting the long-term prognosis. The two highly predictable procedures considered for the same are implant therapy and endodontic treatment. Endodontic treatment and successive post core and final restoration had been the treatment of choice for decades. However, the changing trends in implant dentistry have brought a paradigm shift from treating and preserving a severely compromised tooth by endodontics to extracting it and replacing it with an implant. ${ }^{1}$ Preservation of surrounding structures especially the bone and predictability of the treatment are essential in selecting the treatment option.

Undoubtedly, alveolar/cortical bone plays a key role in providing support to the teeth as well as implants, which are anchored to the bone by desmodontal fibers and osseointegration respectively. Therefore, the treatment rendered should be planned with the ultimate goal to preserve the bone and surrounding structures. ${ }^{2}$ Alveolar bone resorption can occur due to a variety of factors, such as endodontic pathology, periodontitis, trauma, aggressive surgical procedures during implant therapy, or surgical management of periapical infection. ${ }^{3,4}$ Periapical infections have been proven to be the root cause of alveolar bone resorption especially in case of maxillary teeth where buccal/labial plate is thin and porous. This results in the spread of the infection more palatally, resulting in considerable loss of alveolar height. This resultant bone loss may later require an additional augmentation procedure. Hence, preservation of alveolar bone by treating and preventing the recurrent periapical infection will spare additional augmentation procedure. ${ }^{5}$ Stress, regardless of its cause, always produces an alarming reaction, which increases the rate of bone resorption. ${ }^{6}$ Reduction or distribution of mechanical stress, i.e., applied on the alveolar bone could drastically improve the blood flow and hence, favor preservation. 


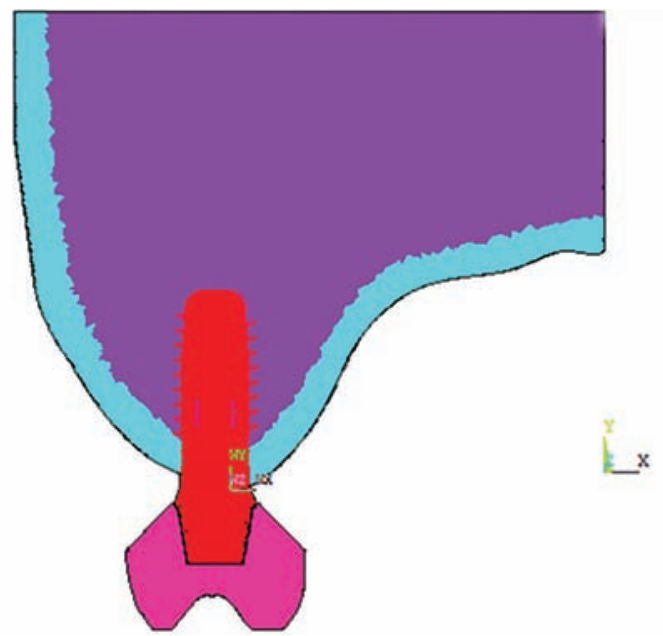

Fig. 1: Single tooth implant model (Model-I)

Implant prognosis is greatly influenced by the amount and direction of load applied. ${ }^{7}$ Excessive masticatory load due to improper treatment planning can result in early crestal bone loss as well as early implant failure, which are not uncommon. Also, consequences of excessive masticatory load may lead to failure in endodontically ${ }^{8}$ and post core-treated tooth, which in turn results in bone resorption especially on buccal plate or ankylosis due to periodontal ligament resorption. ${ }^{5}$

Numerous factors have been shown to contribute to the predictability of both implant and endodontically treated teeth, but success in implant is different than success for endodontics. ${ }^{9}$ Success of implant depends on quality and quantity of bone, masticatory load, and type of restoration and implant design, whereas the factors that have been linked to success of endodontically treated and restored tooth relies on periodontal condition and quality of the restoration. ${ }^{10,11}$ There are also fundamental differences in the oral environments of patients receiving either implant or endodontics therapy. Implants tend to be placed in the context of good oral health, whereas endodontic treatment usually is performed in the presence of active disease. ${ }^{9}$

Due to insufficient information on the comparison of these two treatment modalities, the selection of one over the other is more of operator choice and skill and hence, more subjective. As stress plays a major role in the resorption of bone and directly or indirectly influences the prognosis of both the treatment modalities, it has been considered for this study.

\section{MATERIALS AND METHODS}

For the purpose of this study, two computer-generated isotropic and homogeneous finite element analysis models were constructed:

Model-I (implant): Single tooth implant restored with crown, surrounded by anatomic structures.

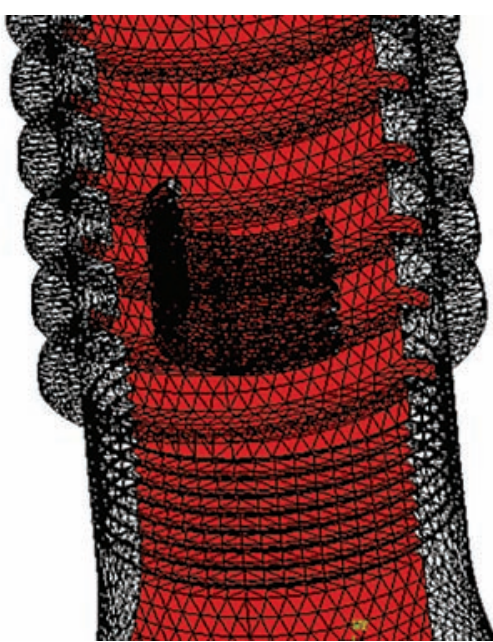

Fig. 2: Meshing of single tooth implant model (Model-I)

Model-P (post core): Endodontically treated tooth, restored with post core and crown, surrounded by anatomic structures.

Graphic preprocessing software-ANSYS version 10was used for creating the geometric representation of Model-I and Model-P with surrounding anatomic structures. These models were of established dimensions possessing the physical properties, such as Young's modulus and Poisson's ratio, of normal anatomic structures and materials utilized to study the stress distribution pattern.

\section{MODEL-I}

Model-I represented an osseointegrated single-tooth implant with a crown, surrounded by isotropic and homogeneous cortical and cancellous bone as seen in Figures 1 and 2. The Young's modulus values used to generate Model-I are tabulated in Table 1. The parameters used to generate Model-I are as follows:

- Residual alveolar bone width: $4 \mathrm{~mm} .{ }^{12}$

- Bone quality: D- $11^{13}$

- Cortical bone thickness: $2 \mathrm{~mm}^{14}$

- Implant - parallel-tapered $\mathrm{Ti}$ alloy $(\mathrm{Ti}, 6 \mathrm{Al}, 4 \mathrm{~V})$ implant ${ }^{15}$

- Abutment - titanium alloy (Ti, 6Al, $4 \mathrm{~V})$

- Connecting screw - titanium alloy $(\mathrm{Ti}, 6 \mathrm{Al}, 4 \mathrm{~V})$

Table 1: Young's modulus and Poisson's ratio for Model-I

\begin{tabular}{llll}
\hline & $\begin{array}{l}\text { Young's } \\
\text { modulus (e) }\end{array}$ & $\begin{array}{l}\text { Poisson's } \\
\text { ratio }(\mathrm{V})\end{array}$ & References \\
\hline Cortical bone & 13.7 & 0.30 & {$[17]$} \\
Cancellous bone & 1.4 & 0.30 & {$[17]$} \\
$\begin{array}{l}\text { Implant body, abutment } \\
\text { and screw (Ti, 6Al, 4V }\end{array}$ & 110 & 0.35 & {$[17]$} \\
$\begin{array}{l}\text { alloy) } \\
\text { Co-Cr metal }\end{array}$ & & & \\
$\begin{array}{l}\text { Porcelain } \\
\text { Resin cement }\end{array}$ & 218 & 0.33 & {$[17]$} \\
\hline
\end{tabular}


- Crown - PFM (Vita metal ceramics and Bellabond $\mathrm{Ni}-\mathrm{Cr}$ alloy coping)

- Luting agent for crown - Panavia F Resin cement ${ }^{16}$

\section{MODEL-P}

Model-P represented a grossly decayed single-rooted maxillary second premolar with $2 \mathrm{~mm}$ of coronal tooth structure remaining postendodontically, restored with post core and porcelain fused to metal (PFM) restoration as seen in Figures 3 and 4. The Young's modulus and Poisson's ratio used for modeling are tabulated in Table 2 and following details were used to generate this model:

- Remaining tooth structure:

- Coronal tooth structure: Class V with no remaining cavity wall with $2 \mathrm{~mm}$ of ferrule all around ${ }^{18}$

- Root length: $14 \mathrm{~mm}^{19}$

- Total length: $16 \mathrm{~mm}$ (root length + remaining tooth structures)

- Surrounding structure:

- Cementum: $0.12 \mathrm{~mm}^{20}$

- Periodontal membrane: $0.2 \mathrm{~mm}^{20}$

- Bone quality: D-1 ${ }^{13}$

- Cortical bone thickness: $2 \mathrm{~mm}^{14}$

- Post and core specification:

- Remaining gutta percha after post space preparation: $4 \mathrm{~mm}^{21}$

- Post space preparation width: $1.1 \mathrm{~mm}^{21}$

- Post used: Parallel-tapering fiber post ${ }^{21}$

- Post diameter ${ }^{21}$

- Apical - $1 \mathrm{~mm}$

- Coronal - $1.8 \mathrm{~mm}$

- Luting agent for post - Panavia F resin cement ${ }^{16}$

- Core-Dual-cure titanium-reinforced composite resin (Ti-core)

- Crown - PFM crown (Vita metal ceramics and Bellabond Ni-Cr alloy coping)

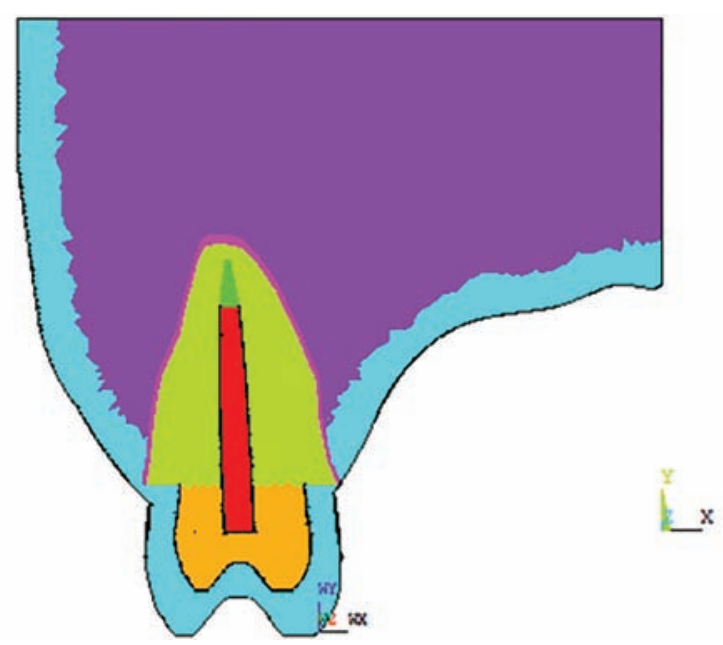

Fig. 3: Post core-treated model (Model-P)
Table 2: Young's and Poisson's ratio for Model-P

\begin{tabular}{llll}
\hline Material & $\begin{array}{l}\text { Young's } \\
\text { modulus }(e)\end{array}$ & $\begin{array}{l}\text { Poisson's } \\
\text { ratio }(\mathrm{v})\end{array}$ & Reference \\
\hline Cortical bone & 13.7 & 0.30 & {$[17]$} \\
Cancellous bone & 1.37 & 0.30 & {$[17]$} \\
Cementum & 18.6 & 0.31 & {$[23]$} \\
Periodontal ligament & 0.0689 & 0.45 & {$[24]$} \\
Dentin & 18.6 & 0.31 & {$[24]$} \\
Mucosa & 10 & 0.40 & {$[23]$} \\
Fiber post & 15.0 & 0.28 & {$[24]$} \\
Resin cement & 8.0 & 0.30 & {$[16]$} \\
Porcelain & 82.8 & 0.35 & {$[17]$} \\
Co-Cr metal & 218 & 0.33 & {$[17]$} \\
\hline
\end{tabular}

- Thickness of metal coping was $0.5 \mathrm{~mm}$ and porcelain thickness used was $1.3 \mathrm{~mm} .^{22}$

- Luting agent for crown - Panavia F Resin cement ${ }^{16}$

Each finite element model was divided into small elements. Each element was interconnected at a number of discrete points called nodes. Each model was meshed by elements defined by 4 to 12 nodes. The displacement of each of these nodes was calculated to determine the maximum Von Mises stress throughout the structure. The types of elements and nodes used for this study were tetrahedron and four-noded shell elements in configuration. Number of elements and nodes used in Model-I was 940,994 and 184,490 respectively, and for Model-P it was 549,298 and 107,349 respectively. The result depicted maximum stress concentration in red and minimum stress in blue. Each of these models was subjected to varying loading conditions in axial and nonaxial directions.

Force and direction in which force is applied:

$$
\begin{aligned}
& 0^{\circ}-300 \mathrm{~N}, 400 \mathrm{~N}, 500 \mathrm{~N} \\
& 15^{\circ}-300 \mathrm{~N}, 400 \mathrm{~N}, 500 \mathrm{~N} \\
& 45^{\circ}-300 \mathrm{~N}, 400 \mathrm{~N}, 500 \mathrm{~N}
\end{aligned}
$$

The load was applied at a point where functional cusp comes in contact with each other. For maxillary premolar two-point contact was considered, one on mesial marginal

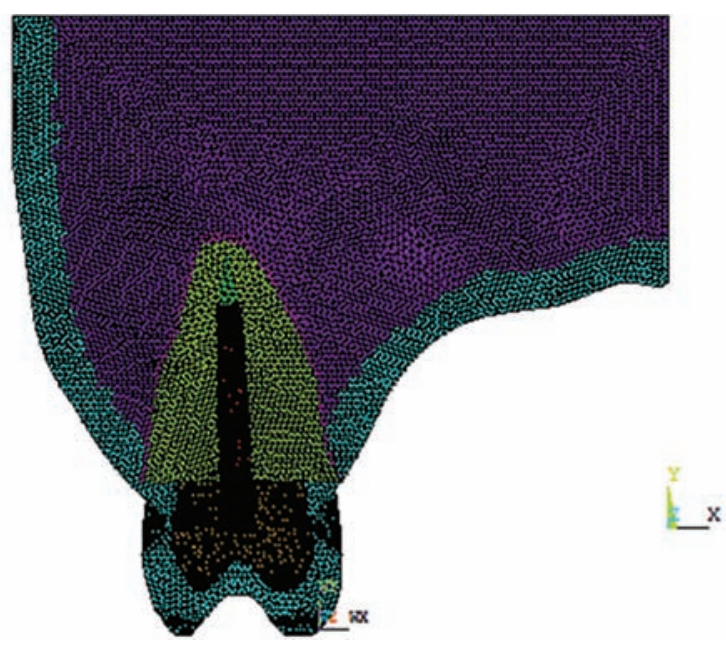

Fig. 4: Meshing of post core-treated model (Model-P) 
ridge and one on the palatal cusp tip. ${ }^{25}$ For nonaxial loading - load was applied at 15 and $45^{\circ}$ from the bottom of the crown. Maximum Von Mises $\left(\Sigma_{\mathrm{v}}\right)$ stress equivalent was observed and compared.

\section{RESULTS}

Here, maximum $\Sigma_{\mathrm{v}}$ (Von Mises) stress produced in cortical bone of Model-I and Model-P under varying loads of $200,300,400$, and $500 \mathrm{~N}$ in axial $\left(0^{\circ}\right)$ and nonaxial $\left(15^{\circ}\right.$, $45^{\circ}$ ) direction was observed and has been tabulated in Table 3 and the same has been represented in Graph 1 .

\section{On $300 \mathrm{~N}$ Loading in Axial and Nonaxial Directions}

At $0^{\circ}$, maximum $\Sigma_{\mathrm{v}}$ stress produced in Model-I was negligibly lesser than that produced in Model-P as seen in Figures 5 and 6.

At $15^{\circ}$, maximum $\Sigma_{\mathrm{v}}$ stress produced in Model-I was negligibly higher than that of Model-P as seen in Figures 7 and 8.
Table 3: Maximum Von Mises stress produced in cortical bone

\begin{tabular}{llll}
\hline Load & Direction & Model-I & Model-P \\
\hline $300 \mathrm{~N}$ & $0^{\circ}$ & 37.6564 & 47.313 \\
& $15^{\circ}$ & 68.5319 & 65.9917 \\
& $45^{\circ}$ & 136.356 & 88.9465 \\
$400 \mathrm{~N}$ & $0^{\circ}$ & 50.2086 & 63.0839 \\
& $15^{\circ}$ & 91.3759 & 87.989 \\
& $45^{\circ}$ & 181.808 & 118.595 \\
$500 \mathrm{~N}$ & $0^{\circ}$ & 62.7607 & 63.0839 \\
& $15^{\circ}$ & 114.22 & 87.989 \\
& $45^{\circ}$ & 227.26 & 118.595 \\
\hline
\end{tabular}

At $45^{\circ}$, maximum $\Sigma_{\mathrm{v}}$ stress produced on Model-I was approximately two times higher than that produced in Model-P as seen in Figures 9 and 10.

\section{On $400 \mathrm{~N}$ Loading in Axial and Nonaxial Directions}

At $0^{\circ}$, maximum $\Sigma_{\mathrm{v}}$ stress produced in Model-I was negligibly lesser than that of Model-P as seen in Figures 11 and 12 .

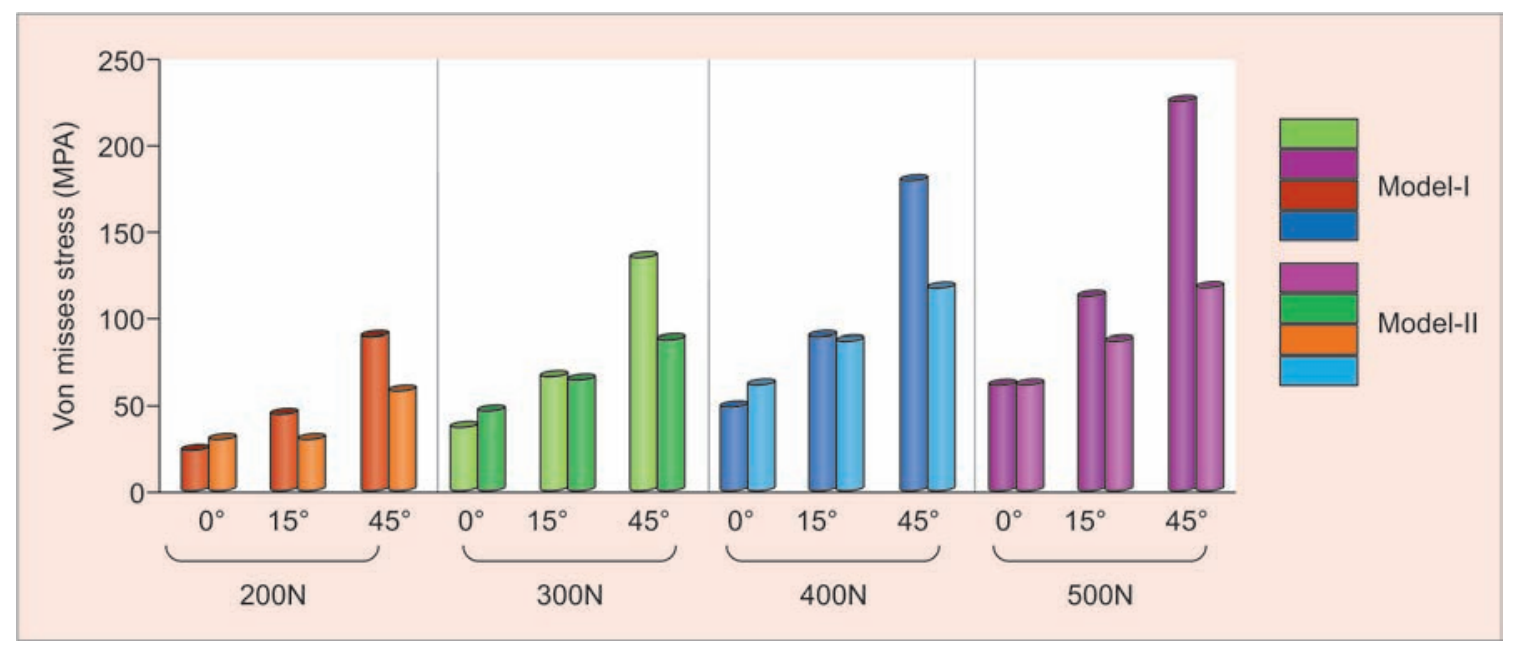

Graph 1: Stress produced in cortical bone of Model-I and Model-P
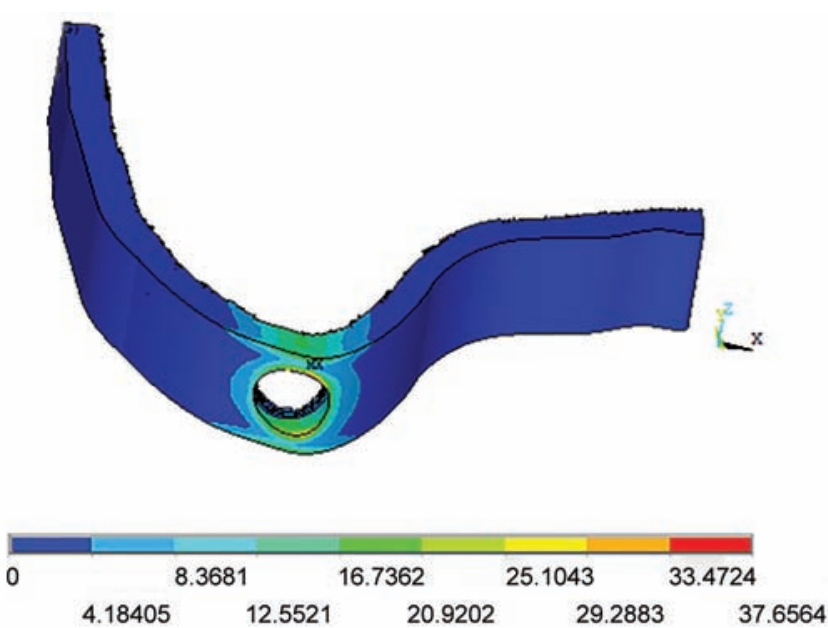

Fig. 5: Stress produced in cortical bone of Model-I at $300 \mathrm{~N}$ force at $0^{\circ}(37.6 \mathrm{MPa})$
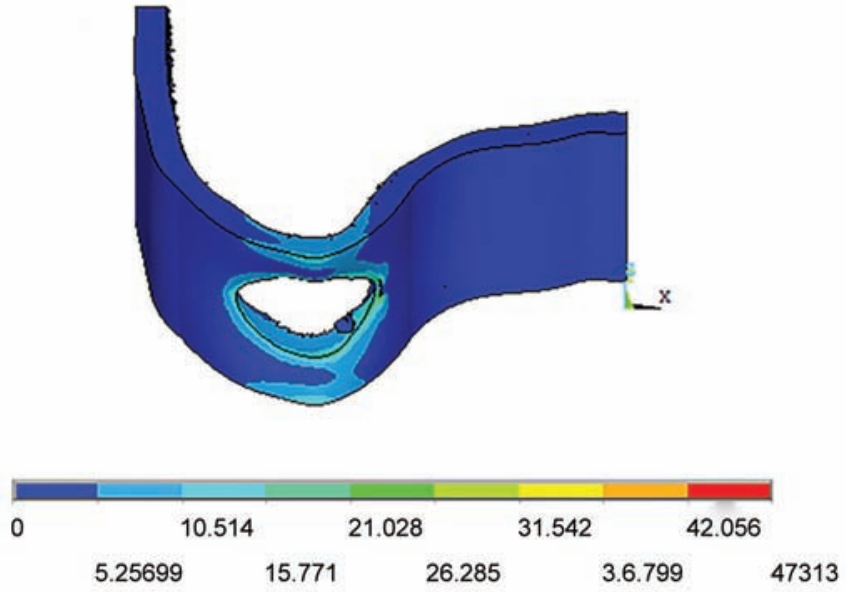

Fig. 6: Stress produced in cortical bone of Model-P at $300 \mathrm{~N}$ force at $0^{\circ}(47.3 \mathrm{MPa})$ 

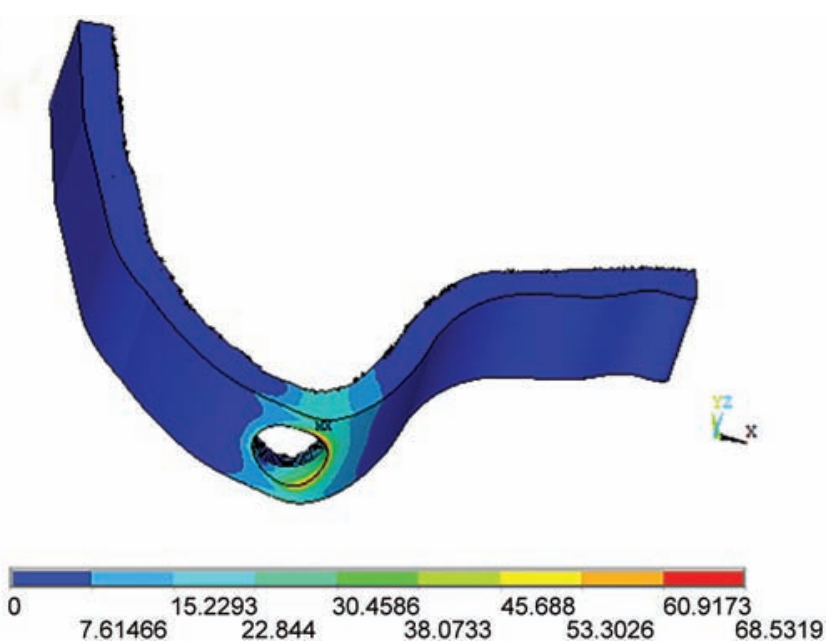

Fig. 7: Stress produced in cortical bone of Model-I at $300 \mathrm{~N}$ force at $15^{\circ}(68.5 \mathrm{MPa})$

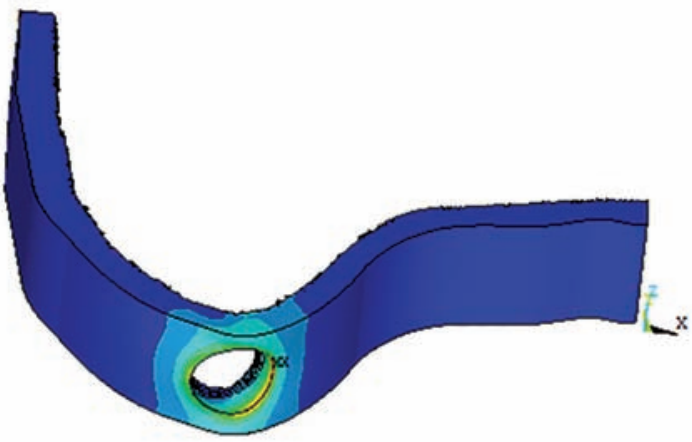

$$
0
$$
30.3013

$\begin{array}{llll}15.1507 & 45.452 & 75.7533 & 106.055\end{array}$

$\begin{array}{llll}15.1507 & 45.452 & 75.7533 & 106.055\end{array}$

60.6026

$\begin{array}{llll}15.1507 & 45.452 & 75.7533 & 106.055\end{array}$

$90.904 \quad 121.205$ force at $45^{\circ}(136.3 \mathrm{MPa})$
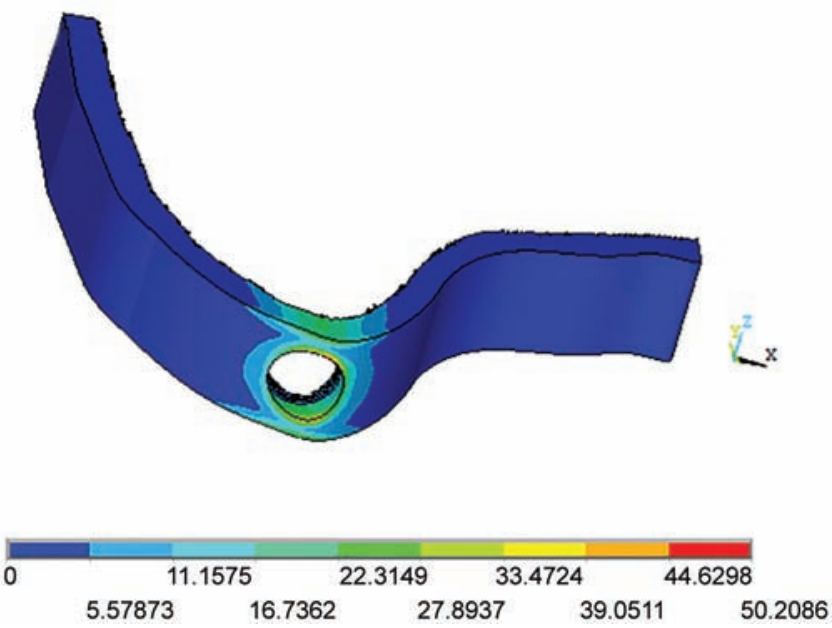

Fig. 11: Stress produced in cortical bone of Model-I at $400 \mathrm{~N}$ force at $0^{\circ}(50.2 \mathrm{MPa})$
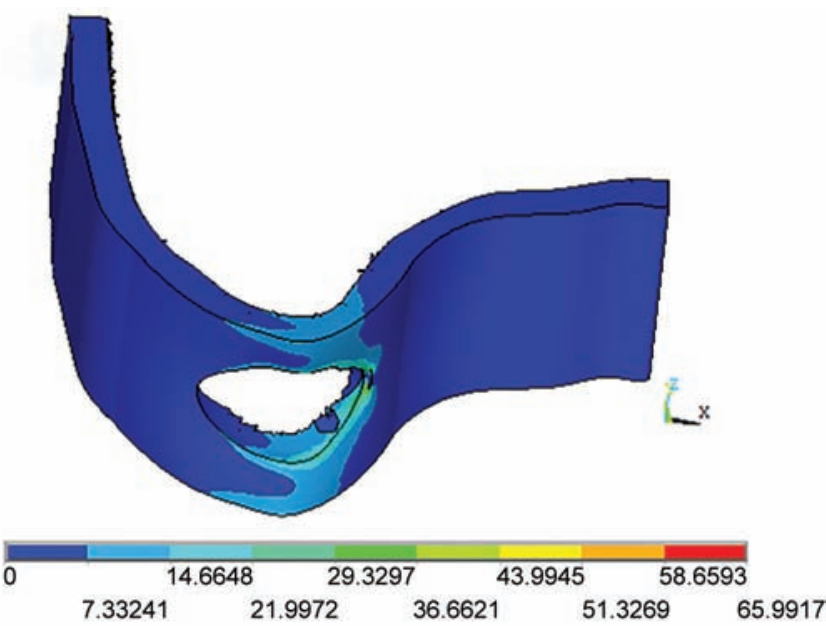

Fig. 8: Stress produced in cortical bone of Model-P at $300 \mathrm{~N}$ force at $15^{\circ}(65.9 \mathrm{MPa})$

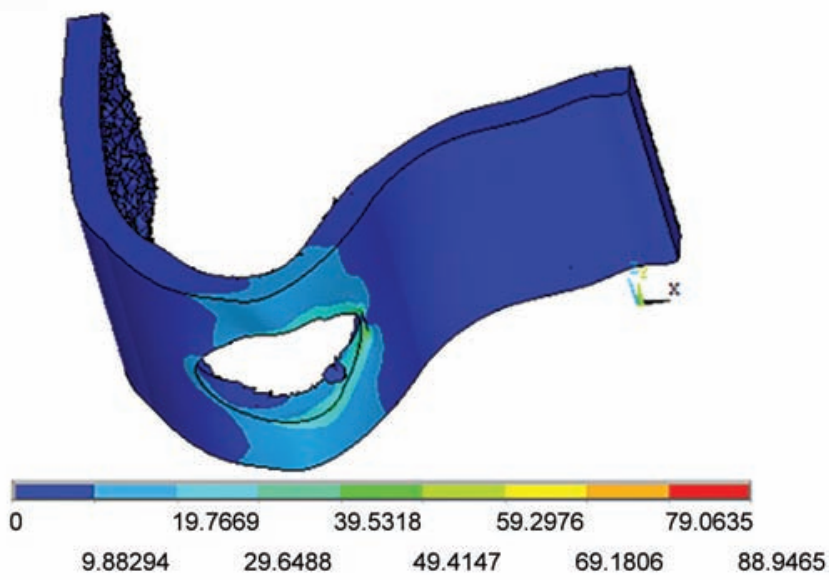

Fig. 10: Stress produced in cortical bone of Model-P at $300 \mathrm{~N}$ force at $45^{\circ}(88.9 \mathrm{MPa})$
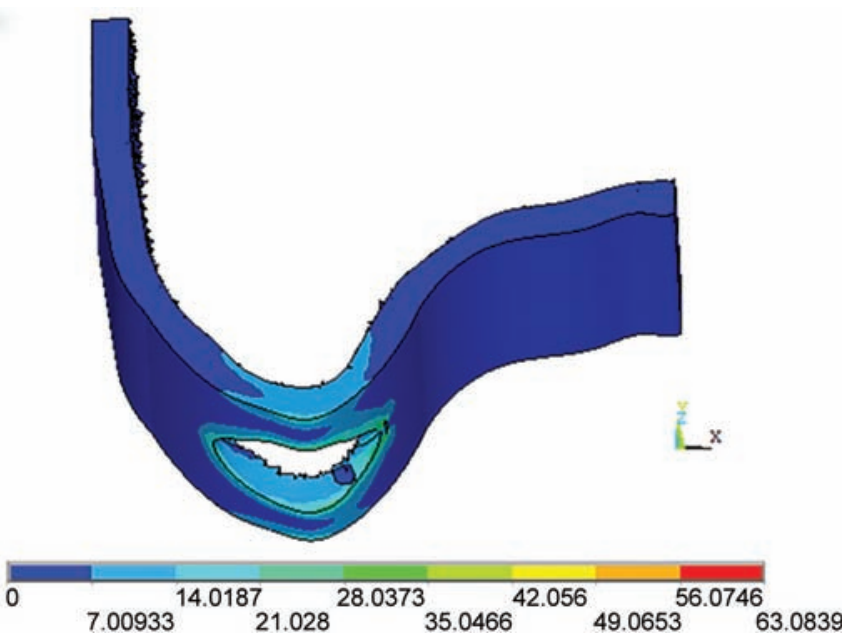

Fig. 12: Stress produced in cortical bone of Model-P at $400 \mathrm{~N}$ force at $0^{\circ}(63.08 \mathrm{MPa})$ 

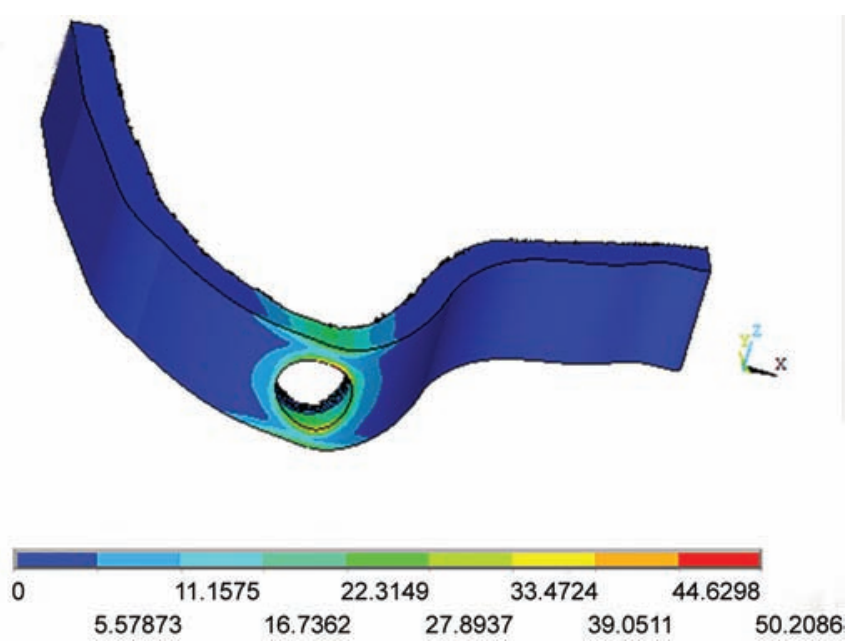

Fig. 13: Stress produced in cortical bone of Model-I at $400 \mathrm{~N}$ force at $15^{\circ}(91.3 \mathrm{MPa})$
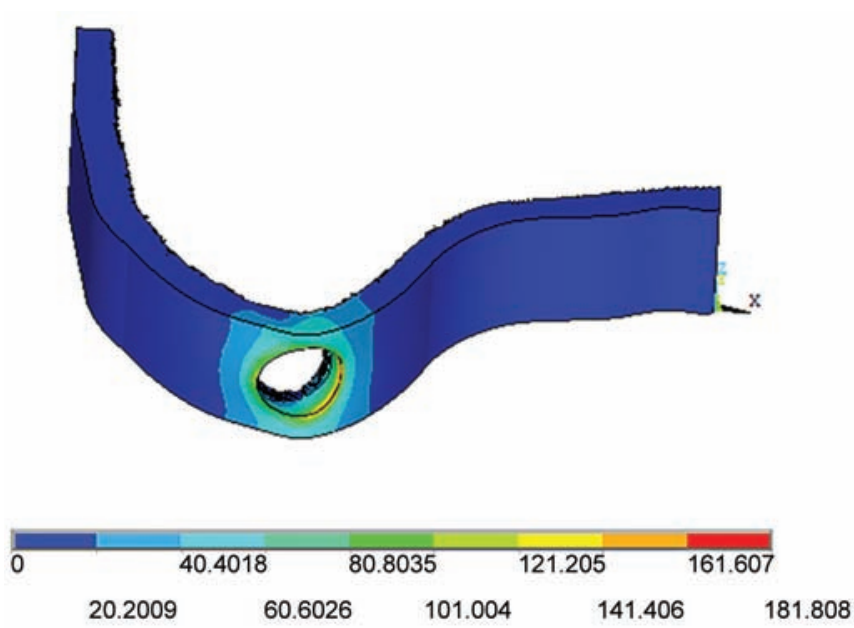

Fig. 15: Stress produced in cortical bone of Model-I at $400 \mathrm{~N}$ force at $45^{\circ}(181.8 \mathrm{MPa})$

At $15^{\circ}$, maximum $\Sigma_{\mathrm{v}}$ stress produced in Model-I was negligibly higher than that Model-P as seen in Figures 13 and 14.

At $45^{\circ}$, maximum $\Sigma_{\mathrm{v}}$ stress produced in Model-I was two times higher than that produced in Model-P, as seen in Figures 15 and 16.

\section{On $500 \mathrm{~N}$ Loading in Axial and Nonaxial Direction}

At $0^{\circ}$, maximum $\Sigma_{\mathrm{v}}$ stress produced in both the models showed no significant difference, as seen in Figures 17 and 18 .

At $15^{\circ}$, maximum $\Sigma_{\mathrm{v}}$ stress produced in Model-I was two times higher than Model-P, as seen in Figures 19 and 20 .

At $45^{\circ}$, maximum $\Sigma_{\mathrm{v}}$ stress produced in Model-I was approximately two times higher than Model-P, as seen in Figures 21 and 22.

On comparing maximum $\Sigma_{\mathrm{v}}$ stress produced in cortical bone of Model-I and Model-P on axial loading,

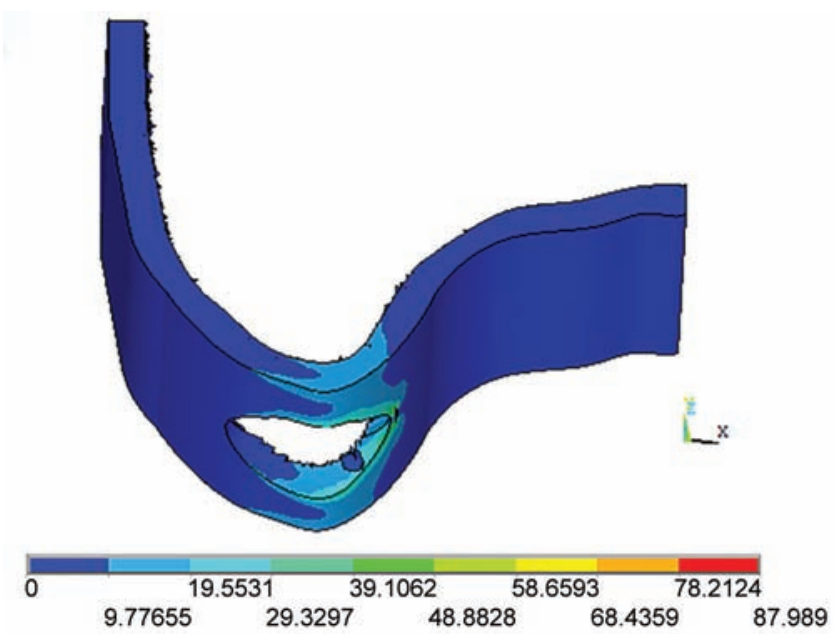

Fig. 14: Stress produced in cortical bone of Model-P at $400 \mathrm{~N}$ force at $15^{\circ}(87.9 \mathrm{MPa})$

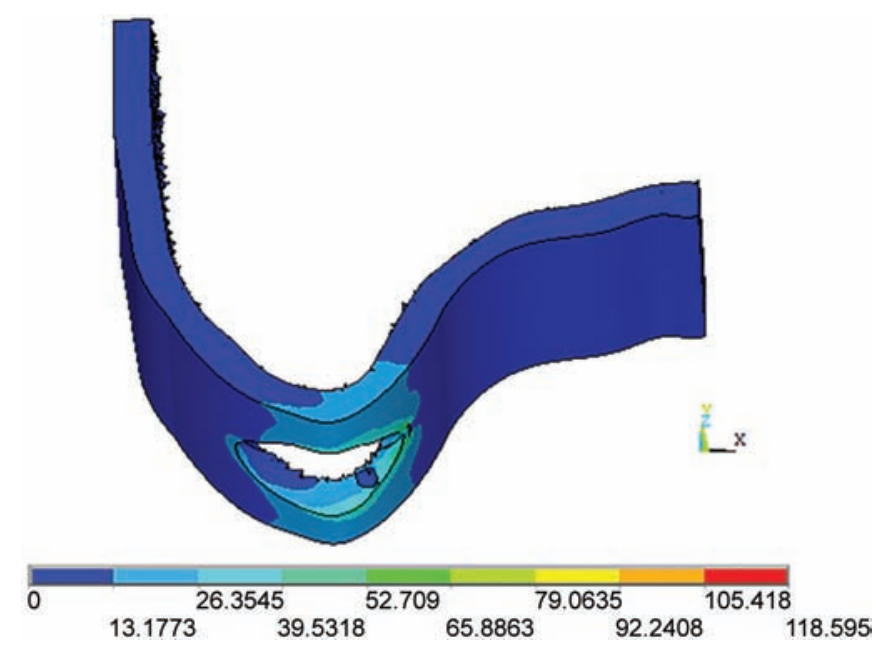

Fig. 16: Stress produced in cortical bone of Model-P at $400 \mathrm{~N}$ force At $45^{\circ}(118.5 \mathrm{MPa})$
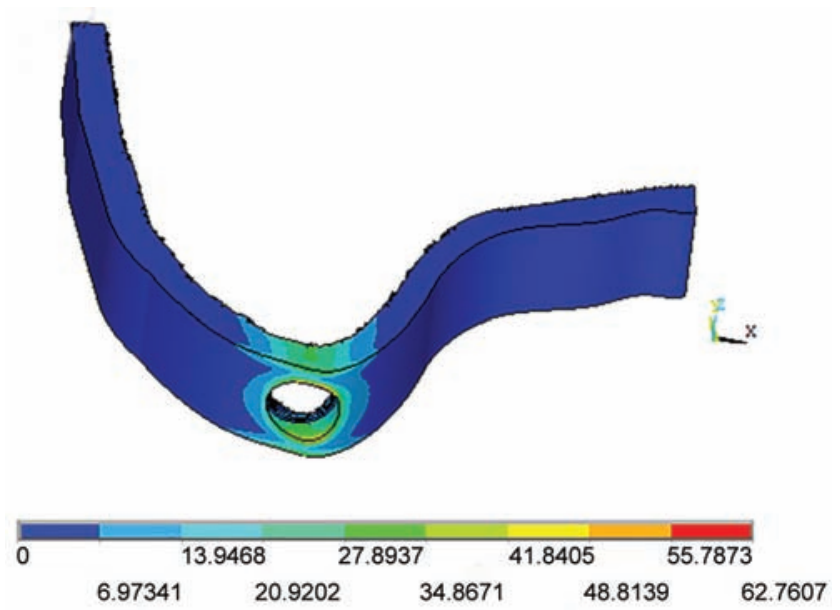

Fig. 17: Stress produced in cortical bone of Model-I at $500 \mathrm{~N}$ force at $0^{\circ}(62.7 \mathrm{MPa})$

it was observed that stress produced in Model-I was negligibly lesser than that produced in Model-P, which is of not much significance. On nonaxial loading of $15^{\circ}$, stress produced was higher in Model-I when 

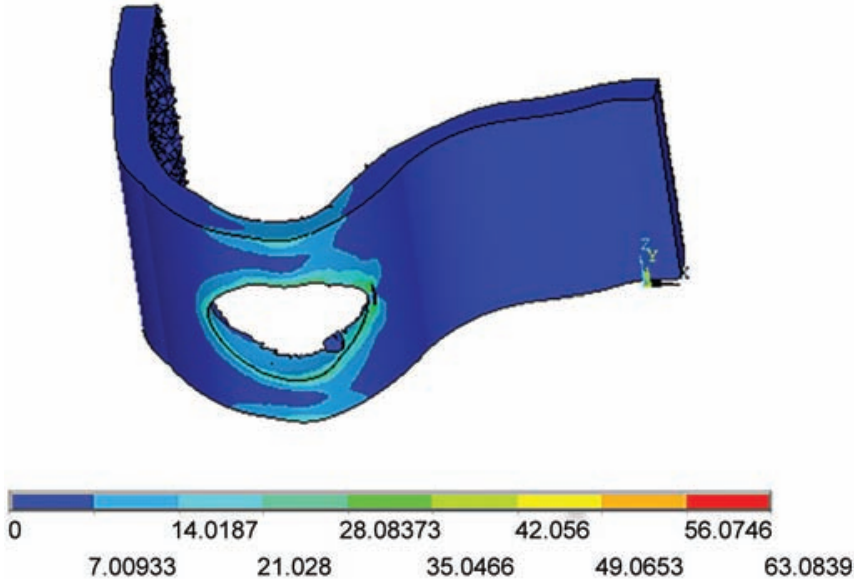

Fig. 18: Stress produced in cortical bone of Model-P at $500 \mathrm{~N}$ force at $0^{\circ}(63.08 \mathrm{MPa})$

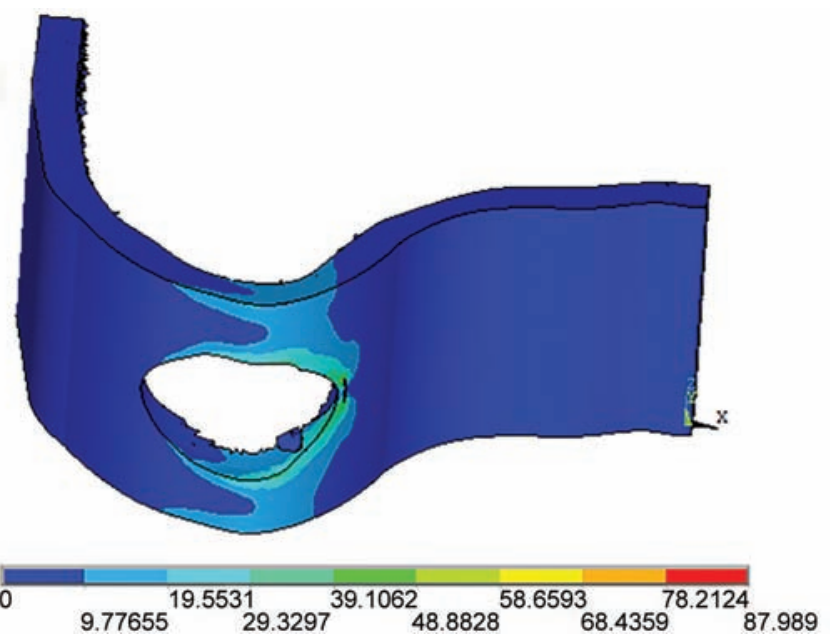

Fig. 20: Stress produced in cortical bone of Model-P at $500 \mathrm{~N}$ force at $15^{\circ}(87.9 \mathrm{MPa})$
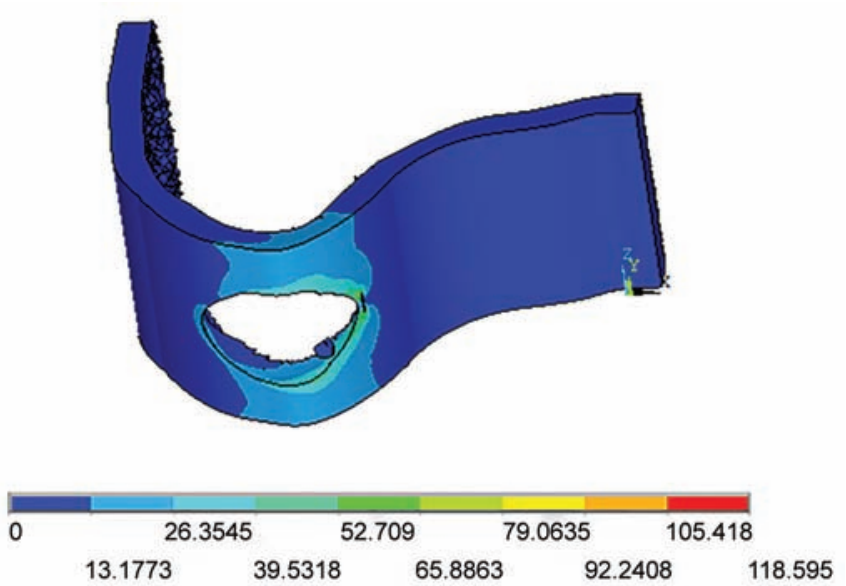

Fig. 22: Stress produced in cortical bone of Model-P at $500 \mathrm{~N}$ force at $45^{\circ}(118.5 \mathrm{MPa})$

compared with Model-P but not of much significance. But on nonaxial loading of $45^{\circ}$, stress produced was significantly higher (almost two times) in Model-I than Model-P.
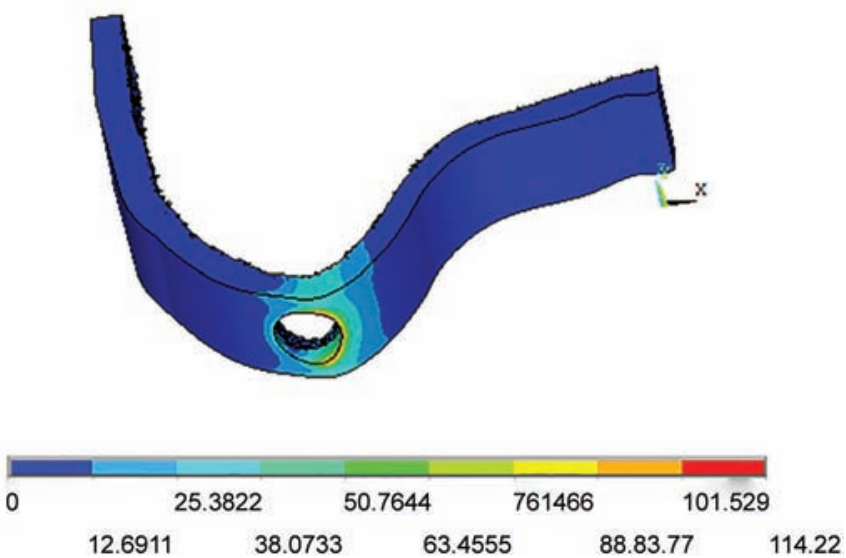

Fig. 19: Stress produced in cortical bone of Model-I at $500 \mathrm{~N}$ force at $15^{\circ}(114.2 \mathrm{MPa})$
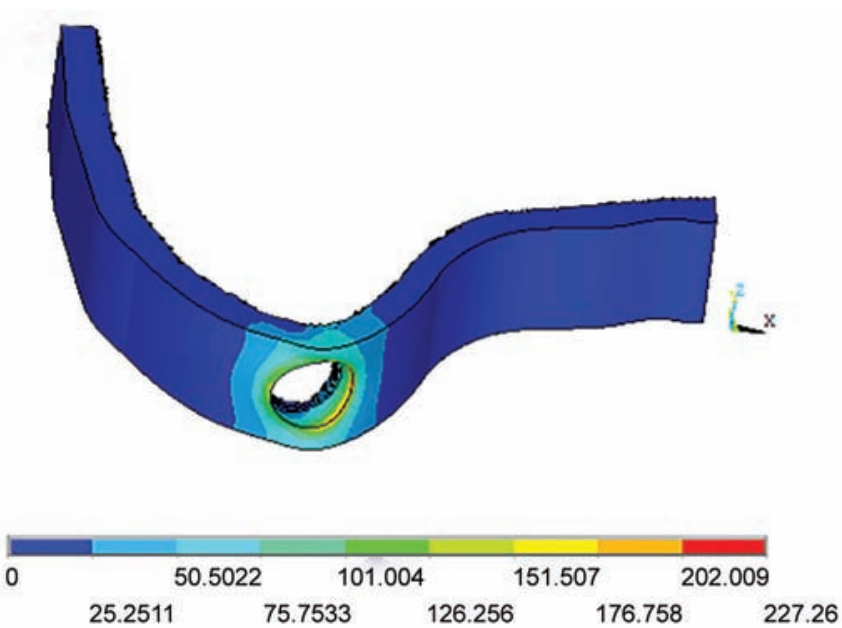

Fig. 21: Stress produced in cortical bone of Model-I at $500 \mathrm{~N}$ force at $45^{\circ}(227.2 \mathrm{MPa})$

\section{DISCUSSION}

Both endodontics and implant therapy were compared in this study in order to assist decision-making of whether to retain a tooth requiring endodontics and post core placement or to extract the same and replace it with implant. ${ }^{26}$ Various studies have been conducted to compare both the treatment modalities, but due to insufficient data regarding success criteria among both the treatments, direct comparison becomes subjective. ${ }^{10}$ Although few studies have compared these two treatment modalities based on the success and survival rate, it had been concluded that implant-supported single crowns have a success rate, i.e., generally superior to the success rate associated with nonsurgical endodontic and post core-treated tooth. ${ }^{27} \mathrm{But}$ the survival rates for implant-supported single crowns and root canal-treated tooth are almost similar., ${ }^{90,27,28}$

Functional occlusal loading on an implant triggers the remodeling of the surrounding alveolar bone. A mild load induces a bone remodeling response and reactive woven bone production. However, excessive loads result in 
microfractures, which in turn cause osteoclastogenesis. ${ }^{29}$ When the bone remodeling capacity is insufficient to keep pace with the microdamage, these defects accumulate and coalesce to form a bigger defect. ${ }^{27}$ As a consequence, the defect formed will fill with fibrous tissues and microorganisms. Eventually, severe bone loss occurs, decreasing the bony support around the implant and increasing the risk of implant failure. . $^{30,31}$

Endodontically treated tooth are more brittle due to loss of structural integrity associated with access preparation or caries. Vertical root fracture is a common complication to root canal therapy that often calls for tooth extraction. It may be initiated during the filling procedure or subsequently because of stress factors maintained by forces of mastication. The typical pattern of bone resorption facing these teeth was described as "dehiscence" and was found in the buccal plate in $90 \%$ of the cases. ${ }^{2}$ Destruction of the supporting tissues, opposite to the fracture as a result of the constant release of irritants including bacterial elements to the area, precludes any treatment other than extraction. Vertical root fracture is most often seen in maxillary and mandibular premolars. ${ }^{5}$

Both the models were embedded in D-1 quality of bone and $2 \mathrm{~mm}$ of cortical bone ${ }^{14}$ as it has showed to have more homogeneous stress distribution. Sevimay et $\mathrm{al}^{13}$ conducted a study to investigate the effect of four different bone qualities on stress and concluded that stress concentrations in D3 and D4 bone qualities reached the highest values at the neck of the implant and were distributed locally. A more homogeneous stress distribution was seen in the entire bone for bone groups D1 and D2, and a similar stress distribution was observed.

For Model-I, parallel-tapered titanium implant (3.75 diameter and $10 \mathrm{~mm}$ length) was selected as it offers advantage of both parallel (more surface area and better stress distribution) and tapered (improved primary stability). ${ }^{15}$ Implant was assumed to be placed in correct axial inclination so straight screw-type titanium abutment was considered in the study. Implant design was selected based on the stress produced by that particular parameter. For the study, square threads with thread pitch were $0.8 \mathrm{~mm}$ and thread width was selected to be $0.4 \mathrm{~mm} .^{32}$ Also, microthreads were included in the design as it provides better implant stability and more surface area. ${ }^{33}$

For Model-P, class V (no remaining wall with $2 \mathrm{~mm}$ of ferrule) was considered for the study because it is the most difficult clinical situation to restore. ${ }^{18}$ To restore this type of clinical situation, fiber post $(1.8 \mathrm{~mm})$, composite resin core, and PFM crown were considered. Fiber post and composite resin core were selected for the study as they have elastic modulus similar to that of dentin, and they tend to have a better biomechanical performance and homogeneous stress distribution. ${ }^{21}$
Cement used in both the models was resin cement as it proved better in strength and also it adheres to the substance and acts as single unit and hence, shows better stress distribution. Also, both the models were restored with PFM crown. ${ }^{16}$

It has been observed by various studies that the normal bite force ranges from 200 to $300 \mathrm{~N}$, with maximum bite force reaching up to $700 \mathrm{~N}$ during parafunction. ${ }^{32}$ Hence, in order to evaluate stresses in normal and parafunctional situations, load considered for the purpose of study were 300,400 , and $500 \mathrm{~N}$. Also, loads were observed in both axial $\left(0^{\circ}\right)$ and nonaxial $\left(15^{\circ}, 45^{\circ}\right)$ directions in order to simulate oral conditions.

Preservation of alveolar bone being the ultimate goal in both the treatment modalities, stress produced in cortical bone was evaluated. It was observed that on axial loading, stress produced in cortical bone showed no significant difference. But on nonaxial loading, stress produced was more in Model-I. According to stress hypothesis ${ }^{34}$ of early crestal bone loss which is based on mathematical principle, when two objects with different Young's modulus come in contact without any intervening substance, stress concentration will be expected at the area where they first come in contact. As titanium and bone have significant difference in the Young's modulus than bone and tooth, more stress is produced in implant ${ }^{27}$ bone interface resulting in loss of bone. The result of the present study also indicated the same.

\section{CONCLUSION}

Within the limitation of this study, it is concluded that axial loading affects both the treatment modalities in a similar manner. However, nonaxial loading generated significantly higher stresses resulting in greater amount of cortical bone loss in the implant model than post coretreated tooth model. Hence, given a choice, this study favors retaining and restoring a compromised tooth with post core and crown rather than extracting and replacing with an implant-supported crown.

Though the study was designed to simulate the oral conditions, a supporting in vivo study of the same order would remove any limitations of the present study. Including various clinical scenarios like parafunctional habits, systemic disorders, etc. could be the future scope of the study.

\section{REFERENCES}

1. Torabinejad M, Goodacre CJ. Endodontic or dental implant therapy: the factors affecting treatment planning. J Am Dent Assoc 2006 Jul;137(7):973-977.

2. Levin I, Ashkenazi M, Schwartz-Arad D. Preservation of alveolar bone of un-restorable traumatized maxillary incisors for future. Refuat Hapeh Vehashinayim (1993) 2004 Jan;21(1):54-59, 101-102. 
3. Coxhead LJ. Reasons for extractions in general practice. New Zealand Dent J 1960 Oct;56:182-183.

4. Marcus SE, Drury TF, Brown LJ, Zion GR. Tooth retention and tooth loss in the permanent dentition of adults: United States, 1988-1991. J Dent Res 1996 Feb;75 Spec No:684-695.

5. Tamse A. Vertical root fractures in endodontically treated teeth: diagnostic signs and clinical management. Endodontic Topics 2006 Mar;13(1):84-94.

6. Ortman HR. Factors of bone resorption of the residual ridge. J Prosthet Dent 1962 May;12(3):429-440.

7. Meffert RM. Issues related to single-tooth implants. J Am Dent Assoc 1997 Oct;128(10):1383-1390.

8. John V, Chen S, Parashos P. Implant or the natural tooth - a contemporary treatment planning dilemma? Aust Dent J 2007 Mar;52(Suppl 1):S138-S150.

9. Hannahan JP, Eleazer PD. Comparison of success of implants versus endodontically treated teeth. J Endod 2008 Nov;34(11): 1302-1305.

10. Morris MF, Kirkpatrick TC, Rutledge RE, Schindler WG. Comparison of nonsurgical root canal treatment and singletooth implants. J Endod 2009 Oct;35(10):1325-1330.

11. Iqbal MK, Kim S. A review of factors influencing treatment planning decisions of single-tooth implants versus preserving natural teeth with nonsurgical endodontic therapy. J Endod 2008 May;34(5):519-529.

12. Pietrokovski J, Starinsky R, Arensburg B, Kaffe I. Morphologic characteristics of bony edentulous jaws. J Prosthodont 2007 Mar-Apr;16(2):141-147.

13. Sevimay M, Turhan F, Kiliçarslan MA, Eskitascioglu G. Threedimensional finite element analysis of the effect of different bone quality on stress distribution in an implant-supported crown. J Prosthet Dent 2005 Mar;93(3):227-234.

14. Al-Khafagy HH. A three dimensional finite element analysis of the effect of cortical bone thickness on the stress distribution around single unit osseointegrated implants. Int Dent SA 2006;8(5):50-54.

15. Lee JH, Frias V, Lee KW, Wright RF. Effect of implant size and shape on implant success rates: a literature review. J Prosthet Dent 2005 Oct;94(4):377-381.

16. Fu G, Deng F, Wang L, Ren A. The three-dimension finite element analysis of stress in posterior tooth residual root restored with postcore crown. Dent Traumatol 2010 Feb;26(1):64-69.

17. Akagawa Y, Sato Y, Teixeira ER, Shindoi N, Wadamoto M. A mimic osseointegrated implant model for three-dimensional finite element analysis. J Oral Rehab 2003 Jan;30(1):41-45.

18. Peroz I, Blankenstein F, Lange KP, Naumann M. Restoring endodontically treated teeth with posts and cores - a review. Quintessence Int 2005 Oct;36(9):737-746.
19. Ash, MM.; Nelson, SJ. Wheeler's dental anatomy, physiology and occlusion. 8th ed. 2009, Saunders, an imprint of Elsevier, Missouri

20. Michael G. Newman, Henry H. Takei, Fermin A. Carranza's clinical periodontology. 9th ed. 2003,Saunders, an imprint of Elsevier, Philadelphia, Pennsylvania.

21. Ingle, JI.; Bakland, LK. Endodontics. 5th ed. 2005,division of Reed Elsevier India pvt Ltd, New Delhi, India.

22. Shillinburg, HT.; Sumiya, H.; Whitsett LD.; Jacobi, R.; Brackett, SE. Fundamentals of fixed prosthodontics. 3rd ed. 1997, Quintessence Publishing Co Ltd, Carol Stream, IL.

23. McLaren JD, McLaren CI, Yaman P, Bin-Shuwaish MS, Dennison JD, McDonald NJ. The effect of post type and length on the fracture resistance of endodontically treated teeth. J Prosthet Dent 2009 Mar;101(3):174-182.

24. Lin $\mathrm{CL}$, Chang $\mathrm{CH}$, Cheng $\mathrm{CS}$, Wang $\mathrm{CH}$, Lee HE. Automatic finite element mesh generation for maxillary second premolar. Comput Methods Programs Biomed 1999 Jun;59(3): 187-195.

25. Dawson, PE. Functional occlusion: from TMJ to smile design.

26. Thomas MV, Beagle JR. Evidence-based decision-making: implants versus natural teeth. Dent Clin North Am 2006 Jul;50(3):451-461, viii.

27. el Askary AS, Meffert RM, Griffin T. Why do dental implants fail? Part II. Implant Dent 1999;8(3):265-277.

28. Doyle SL, Hodges JS, Pesun IJ, Law AS, Bowles WR. Retrospective cross sectional comparison of initial nonsurgical endodontic treatment and single-tooth implants. J Endod 2006 Sep;32(9):822-827.

29. Abuhussein H, Pagni G, Rebaudi A, Wang HL. The effect of thread pattern upon implant osseointegration. Clin Oral Implants Res 2010 Feb;21(2):129-136.

30. Esposito M, Hirsch JM, Lekholm U, Thomsen P. Biological factors contributing to failures of osseointegrated oral implants. (I). Success criteria and epidemiology. Eur J Oral Sci 1998 Feb;106(1):527-551.

31. El-Anwar MI, El-Zawahry MM, El-Mofty M. Load transfer on dental implants and surrounding bones. Aust J Basic Appl Sci 2012;6(3):551-560.

32. BraunS, Bantleon HP,HnatWP, FreudenthalerJW, MarcotteMR, Johnson BE. A study of bite force, part 1: relationship to various physical characteristics. Angle Orthod 1995;65(5): 367-372.

33. Koo KT, Kim YJ, Kim BK, Kang EJ. Effect of dental implant micro thread dimensions on osteoblasts. Implantology. 4-11.

34. Mish, C. Contemporary implant dentistry. 3rd ed. 2010, Mosby Inc, St. Louis, Missouri 